\title{
Mobilidade urbana na área metropolitana de Maputo: análise dos órgãos de gestão do planeamento e mobilidade urbana, arranjos institucionais e insumos para a sua efectiva articulação
}

[Urban mobility in Maputo metropolitan area: analysis of the management bodies of urban planning and mobility, institutional arrangements and inputs for effective articulation]

\author{
Inocêncio Nhatuguês de Mendonça* \\ Pontifical University Catholic of Paraná - Brazil
}

Submitted 6 Nov 2012; received in revised form 24 Mar 2012; accepted 28 Apr 2012

\begin{abstract}
Resumo
Maputo, capital de Moçambique, vê a condição dos deslocamentos e da acessibilidade urbana se agravar na medida em que cresce sua área metropolitana. Mais do que soluções tecnológicas ou implementação de modais, mostra-se necessária a revisão dos instrumentos legais e reestruturação do arranjo institucional no sector de gestão urbana. Com uma breve reflexão sobre o processo de municipalização e política de descentralização em curso em Moçambique, e revisita ao histórico do planeamento urbano em Moçambique, este trabalho pretende fazer o relacionamento deste conjunto de processos com a abordagem feita pelos diversos governos que actuaram na Área Metropolitana de Maputo pois, os actores na gestão e mobilidade urbana em Maputo variam e assumem diferentes papéis ao longo do tempo. Deste modo, como sucede com grande parte das áreas metropolitanas em Moçambique, Maputo clama por um por um arranjo institucional de nível regional-metropolitano de forma a permitir uma melhor coordenação entre os actores no sector de mobilidade.
\end{abstract}

Palavras-Chave: arranjo institucional, mobilidade urbana, planeamento urbano.

\begin{abstract}
Maputo, capital of Mozambique, sees the condition of displacement and urban accessibility worsens as it grows its metropolitan area. More than technological solutions or implementation of modal, it is necessary to review the legal instruments and restructuring of the institutional arrangement in the field of urban management. This work proposes a brief discussion on the process of decentralization policy and municipalisation taken in Mozambique and revisits its urban planning process, it intends to relate this set of processes with the approach taken by the governments that acted in Maputo Metropolitan Area and propose some subsidies for the improvement of public transport policies in the country. Thus, as in other metropolitan areas of Mozambique, the Urban Planning and Mobility sector in Maputo calls for a regional-metropolitan institutional arrangement to allow a better coordination in the urban mobility field.

Key words: institutional arrangement, urban mobility, urban planning.

*Email: arkmenducci@hotmail.com.
\end{abstract}

\section{Recommended Citation}

Mendonça, I. N. (2014) Mobilidade urbana na área metropolitana de Maputo: análise dos órgãos de gestão do planeamento e mobilidade urbana, arranjos institucionais e insumos para a sua efectiva articulação. Journal of Transport Literature, vol. 8, n. 2, pp. 244-270.

- JTL/RELIT is a fully electronic, peer-reviewed, open access, international journal focused on emerging transport markets and published by BPTS - Brazilian Transport Planning Society. Website www.transport-literature.org. ISSN 2238-1031. 


\section{Introdução}

No presente trabalho são apresentados como base de dados uma breve contextualização sobre a relação entre o planeamento urbano e a gestão da mobilidade urbana em Moçambique, e na Área Metropolitana de Maputo especificamente. São principalmente focados nestes pontos, aspectos ligados a instrumentos legais e ao arranjo institucional do sector. Segue-se ainda uma descrição sobre o desenvolvimento da gestão urbana na Área Metropolitana de Maputo, com a apresentação de alguns dados sobre a situação actual do transporte público de passageiros.

Este material possibilitou a execução de uma análise sobre o estágio actual da mobilidade urbana em Maputo, propondo-se a posterior uma revisão dos seus instrumentos legais e arranjo institucional de forma a que seja possível uma efectiva articulação entre os vários órgãos responsáveis pela gestão da mobilidade na Área Metropolitana de Maputo.

$\mathrm{Na}$ actualidade a inevitável metropolização e motorização nos deslocamentos quotidianos são facto em diversas grandes cidades do continente africano que possuem uma democratização recente e com consequente jovem arcabouço político-administrativo. Estas cidades se expandem em escala metropolitana, muitas vezes, sem o respectivo acompanhamento na infraestruturação, quadro técnico, administrativo e legal de gestão urbana.

A capacidade limitada do transporte público, as fracas ligações e os preços altos, implicam que por vezes as pessoas pobres gastem acima de $30 \%$ do seu orçamento no transporte (vide o estudo de caso elaborado pelo Fundo para o Desenvolvimento da Comunidade, 2009).

A questão da mobilidade urbana envolve sua relação com o planeamento do espaço urbano. Seria necessário verificar a consistência dos instrumentos que possibilitariam a implementação de um modelo de gestão de mobilidade urbana em harmonia com o uso e ocupação do solo urbano. E mais do que um plano, o importante para o planeamento e gestão da mobilidade urbana, sobretudo na escala metropolitana, são os arranjos institucionais em diferentes escalas para elaboração, implementação e gestão dos planos produzidos.

De realçar que movimentar-se actualmente nas cidades da Matola e Maputo, em Moçambique, vai-se tornando cada vez mais difícil. O congestionamento do tráfego rodoviário, as condições oferecidas pelos transportadores colectivos aos cidadãos, a qualidade dos serviços de 
acessibilidade ao sistema de transporte e serviços no geral, são problemas actuais das cidades moçambicana.

Como estratégia, o presente trabalho foi orientado para a busca de explicações e interpretações convincentes em relação ao estágio actual da mobilidade urbana na Área Metropolitana de Maputo, sendo a sua gestão o âmago da questão. E aqui incide o primeiro resultado deste trabalho: apesar de não existir oficialmente, pelas interdependências sociais e econômicas, o problema da mobilidade na capital do Moçambique terá inevitavelmente que ser tratado por esta área metropolitana, designação não existente oficialmente, mas que aqui será assumida como sendo a área correspondente a circunscrição territorial formada pelas cidades de Maputo e da Matola, que pelas características resultam numa área urbana conjunta.

Para o desenvolvimento da pesquisa foram usados dados secundários obtidos por meio de análise documental feita em documentos oficiais ou não das instituições ligadas à área de mobilidade urbana na metrópole de Maputo, nas publicações, nos periódicos, nos relatórios teóricos e operacionais das actividades, bem como entrevistas com recolha de entrevistas com técnicos locais.

Feita, neste item, a contextualização sobre o objecto em estudo, os capítulos subsequentes serão compostos pela verificação da consistência dos órgãos de planeamento que possibilitariam a implementação de um modelo de gestão de mobilidade urbana na Área Metropolitana de Maputo, em harmonia com o uso e ocupação do solo urbano.

Portanto, o primeiro capítulo do presente trabalho fará uma breve descrição sobre o histórico da mobilidade e gestão urbana em Moçambique. A explanação do estágio actual da mobilidade urbana e da gestão urbana em Moçambique, especificamente na Área Metropolitana de Maputo consta do segundo, terceiro e quarto capítulos.

O quinto capítulo faz uma breve abordagem sobre o relacionamento entre a mobilidade e a gestão urbana na Área Metropolitana de Maputo ficando o sexto capítulo responsável pela conclusão no trabalho. 


\section{Mobilidade e gestão urbana em Moçambique}

Segundo o estudo da Direcção Nacional de Planeamento e Ordenamento Territorial (2006), Moçambique está desde os finais da década 1990, num processo de reforma dos órgãos locais. É possível individualizar os mecanismos de administração do passado, o sistema centralizado - secretários de bairro, chefes de quarteirões e chefes de 10 famílias/10 casas - e o actual sistema descentralizado, presidentes dos conselhos municipais, presidentes das assembleias municipais. Apesar de não reconhecidos, os órgãos de base herdados do sistema centralizado estão ainda implantados nas cidades e com maior protagonismo nas áreas periféricas. Pode-se considerar o actual sistema de misto ou de semi-descentralizado.

Estão definidos dois sistemas de governação local neste âmbito: um sistema centralizado, com órgãos locais do estado, que correspondem aos governadores provinciais, administradores de distrito, chefes de postos administrativos e os chefes de localidades nas províncias, distritos, postos administrativos e localidades, sem nenhuma autonomia, quer administrativa quer financeira; um outro, descentralizado, que corresponde às autarquias, que conta com a participação dos cidadãos, que elegem os seus órgãos deliberativos e executivos ainda conforme relatado no estudo realizado pela Direcção Nacional de Planeamento e Ordenamento Territorial (2006).

Por outro lado, a pesquisa sobre as experiências de municipios no exercício de planeamento urbano e estratégico em Moçambique realizada pelo Conselho Municipal da Cidade de Maputo (2010), alerta sobre o facto de a Política de Ordenamento do Território de Moçambique - BR $^{1}$ I Série, N²2, Resolução 18/2007 de 30 de Maio -, classificar as áreas urbanas tendo em conta a sustentabilidade dos centros urbanos e termos de uso do solo urbano, saneamento e ambiente, desenvolvimento de infraestruturas de transporte e comunicações, com objectivo de (i) promover a sustentabilidade das áreas urbanas, (ii) melhorar a gestão de terrenos urbanos e (iii) garantir um melhor planeamento para o desenvolvimento das zonas urbanas.

Como diz Moura (2008), facto é que os arranjos urbanorregionais extrapolam a cidade enquanto forma física delimitada pelo espaço construído e contínuo, incorporando o desenho de aglomerações urbanas mais extensas e nem sempre contínuas; ao mesmo tempo, assimilam a perspectiva da região, ao polarizarem directamente um território que transcende o

\footnotetext{
${ }^{1}$ Boletim da República de Moçambique.
} 
aglomerado principal e que aglutina outras aglomerações e centros das proximidades, como também espaços rurais. Assumem, dessa forma, uma multidimensionalidade e uma multiescalaridade que demarcam seu carácter complexo, caracterizando-se como uma configuração híbrida entre o urbano e o regional.

No entanto, o pano de fundo para o presente estudo será, em especial, o problema da organização institucional visando a gestão da mobilidade urbana na Área Metropolitana de Maputo, formada principalmente pelas cidades de Maputo e da Matola, contando ainda com parte do distrito de Marracuene e Boane. O foco em Maputo e Matola deve-se pois, ao facto de serem economicamente centrais neste conjunto urbano de escala metropolitana, onde os deslocamentos diários da população têm um papel fundamental na vida urbana.

Será, portanto, em torno das questões aqui apresentadas que a presente pesquisa irá fazer a análise da mobilidade urbana na Área Metropolitana de Maputo, verificando a sua articulação com o planeamento urbano, estudando a viabilidade dos órgãos de gestão urbana existentes na área metropolitana.

\section{Situação actual}

A situação geográfica e estratégica de Moçambique com relação a vários portos marítimos que servem os países vizinhos do interior, determina a existência de corredores de transporte, domésticos e internacionais, que possuem infraestruturas rodoviárias importantes.

Segundo o BR ${ }^{2}$ I Série, No29, Resolução 50/1998 de 28 de Julho, o principal modo de transporte é o rodoviário que garante a movimentação de cerca de $10 \%$ de cargas e $90 \%$ de passageiros, e constitui o meio de acesso aos restantes modos de transporte.

\footnotetext{
${ }^{2}$ Boletim da República de Moçambique.
} 


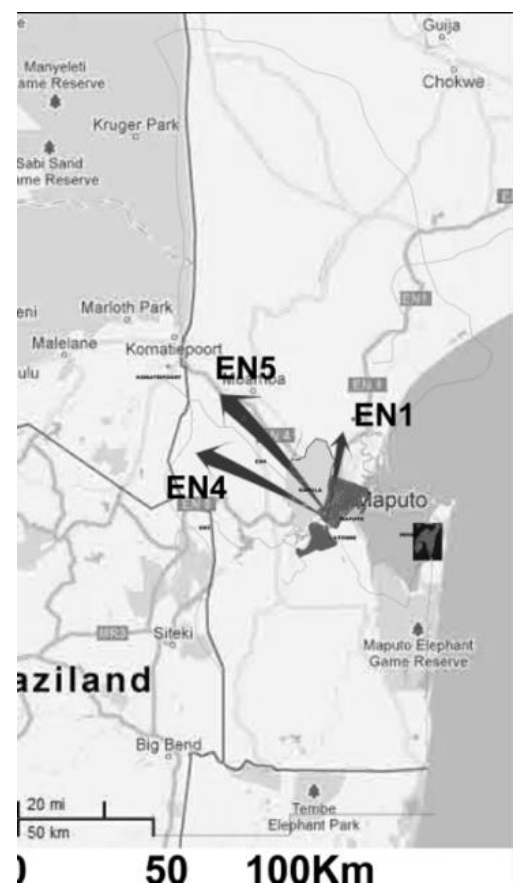

Figura 1 - Localização da Área Metropolitana de Maputo ${ }^{3}$

Pela sua proximidade geográfica e a continuidade física, as cidades de Maputo e da Matola (Figuras 1 e 2), formam uma mesma área urbana, que pode ser designada por área urbana de Maputo ou, porque não, por Área Metropolitana de Maputo.

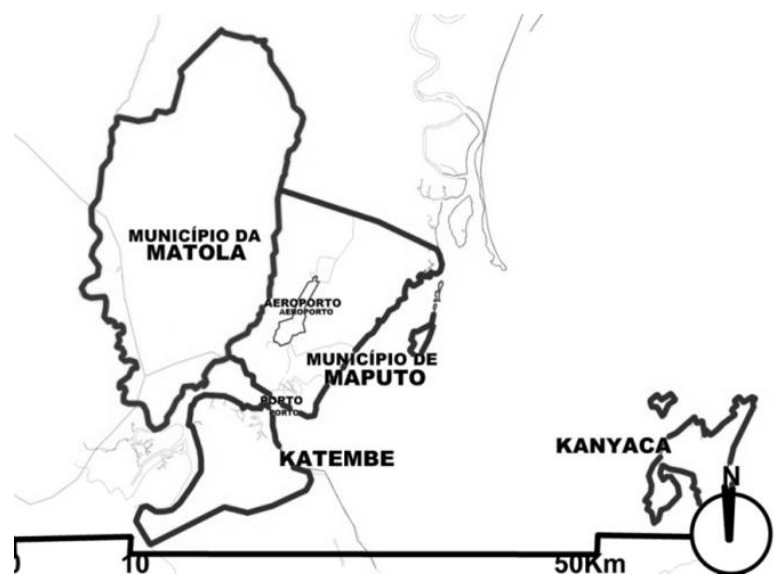

Figura 2 - Área Metropolitana de Maputo ${ }^{3}$

Maputo e Matola estão em um momento decisivo para o melhoramento do estágio da mobilidade urbana: de um lado, o Município de Maputo está elaborando o seu plano de mobilidade com o apoio da JICA (Vide site da Associação de Empresas Moçambicanas de

\footnotetext{
${ }^{3}$ Fonte: o autor.
} 
Consultoria); de outro, é imprecindível a sua elaboração considerando a escala metropolitana, havendo desta maneira a necessidade de interacção com os gestores da cidade da Matola e, distritos de Marracuene, Boane e Moamba. Maputo-Matola é a maior área urbana do país concentrando cerca de $10 \%$ da população nacional e 33\% dos cerca de 6 milhões (Tabela 1) de pessoas que residentes nas zonas urbanas do país.

Tabela 1 - População de Moçambique (1997/2007) ${ }^{4}$

\begin{tabular}{lcc}
\hline \hline & Censo 1997 & Censo 2007 \\
\hline Nacional & 16.075 .708 & 20.530 .714 \\
\hline Urbana & 4.601 .100 & 6.203 .035 \\
\hline Rural & 11.474 .608 & 14.327 .679 \\
\hline Municípios & 4.052 .274 & 5.361 .819 \\
\hline \hline
\end{tabular}

Maputo é a capital e a maior cidade de Moçambique. Localiza-se no sul do país, na margem ocidental da baía de Maputo. Os seus limites são: a norte, o distrito de Marracuene; a noroeste e oeste, a cidade da Matola; a oeste, o distrito de Boane; a sul, o distrito de Matutuíne.

A cidade de Maputo alberga o segundo maior porto da costa oriental de África, ao qual confluem três linhas ferroviárias ligando aos vizinhos Suazilândia, África do Sul e Zimbabwe. A rede rodoviária permite a ligação aos dois primeiros países, por meio das Estradas Nacionais Números 4 e 5 - EN4 e EN5 -, e o resto de Moçambique por meio da Estrada Nacional N1. Em termos de ligações aéreas, Maputo é servida pelo Aeroporto Internacional de Maputo.

Como capital da república, Maputo alberga ainda as instalações do governo, das representações diplomáticas e dos principais organismos internacionais. Além disso, sua localização no extremo sul do país, por prover de acesso marítimo à África do Sul, continua a favorecer a ligação com os países limítrofes, em detrimento da integração nacional, vide o Plano de Estrutura Urbana do Município de Maputo (2008).

A cidade de Maputo possui uma população de 1.150 .000 habitantes $^{5}$, repartidos por três principais áreas o centro da cidade, KaTembe; e as Ilhas de KaNyaca e Xefina. Segundo o

\footnotetext{
${ }^{4}$ Fonte: Instituto Nacional de Estatística de Moçambique (INE).
} 
Plano de Estrutura Urbana de Maputo (2008), calcula-se que densidade bruta da cidade esteja na ordem dos 37 hab/ha, que é uma densidade muito baixa quando comparada com as de muitos outros centros urbanos no mundo e em África.

Segundo Jorge e Melo (2011), Com 308 quilómetros quadrados Maputo é composta por um centro urbanizado, que ocupa aproximadamente $8 \%$ do território, e por uma área, aqui globalmente designada por peri-urbana, dependente deste núcleo central e diferente do mesmo em aspectos como: a qualidade e quantidade de infraestruturas, de equipamentos básicos e de transportes públicos, a diversidade de usos do solo, principalmente de serviços e actividades económicas, as características habitacionais, a capacidade económica e o estilo de vida dos seus habitantes.

Quanto ao município da Matola, conurbado com Maputo, ocupa uma área de 368,4 quilómetros quadrados. É limitado a noroeste e a norte pelo distrito de Moamba; a oeste e sudoeste pelo distrito de Boane. Ao sul, faz fronteira com a cidade de Maputo, através do posto administrativo da KaTembe, separado da baía de Maputo. A este, é também limitado pela cidade de Maputo e a noroeste, faz fronteira com o distrito de Marracuene. A região da baía onde se situa a cidade da Matola é caracterizada por uma vasta área planáltica que se mantém acima dos 40 metros de altitude. A área da cidade é drenada pelo vale do Infulene e pelo rio Matola que desaguam no estuário que forma a baía de Maputo.

A cidade da Matola tem actualmente uma população de 684.263 habitantes ${ }^{6}$, repartidos por três postos administrativos urbanos nomeadamente Matola, Machava e Infulene.

Segundo Moura (2008) há, neste contexto, a necessidade de se considerar que de modo geral, a formação dos arranjos espaciais tem estreitas relações - não obrigatoriedade - com a origem e expansão das aglomerações urbanas decorrentes do processo de urbanização e metropolização, consideradas como principais resultados dos movimentos concentradores do modelo capitalista de produção. Algumas, com o tempo, expandem-se física, económica e funcionalmente absorvendo em uma unidade espacial, contínua ou descontínua, centros urbanos e suas áreas intersticiais urbanas e rurais - um rural transformado. Mais que isso, em seu processo de expansão, estreitam relações e dividem funções com aglomerações vizinhas, dispostas em um raio de aproximadamente $200 \mathrm{~km}$. Conjungam-se em uma mesma unidade,

${ }^{5}$ III Recenseamento Geral da População e Habitação, 2007. INE, Maputo.

${ }^{6}$ Idem. 
propiciando vínculos com aglomerações mais distantes e estendendo sua influência para além dos seus limites administrativos. Esse conjunto reforçado passa a responder pelas dinâmicas mais intensas e mais complexas se comparadas com outras porções do território, caracterizando-se como formação que transcende o padrão das aglomerações urbanas, com uma constituição simples do pólo e periferia, alcançando uma escala mais complexa e, em alguns casos, uma dimensão regional.

\section{O desenvolvimento da gestão urbana na Área Metropolitana de Maputo}

Para Jorge e Melo (2011), as actuais estruturas territoriais das cidades de Maputo e Matola são reflexo de diferentes contextos históricos, destacando-se: (i) o colonial, que esteve na génese da sua formação; (ii) o pós independência, de inspiração socialista; e (iii) o neoliberal, após a abertura à economia de mercado no final da década de 1980. Ao longo do tempo, os processos e dinâmicas de intervenção urbana têm contribuído para, ou sido incapazes de contrariar, a dualidade socioespacial existente, acentuada pela urbanização acelerada - que se inicia na década de 1950 e se intensifica durante a guerra civil - e agravada no presente contexto de globalização neoliberal, segundo autores como Jenkins e Wilkinson (2002) e Raposo (2007).

Actualmente, a cidade de Maputo constitui administrativamente um município com um governo eleito e tem também, desde 1980, o estatuto de província. Não deve ser confundida com a província de Maputo, que ocupa a parte mais meridional do território moçambicano, exceptuando a cidade de Maputo.

A cidade alberga um porto ao qual confluem três linhas ferroviárias que ligam aos países vizinhos (Suazilândia, Africa do Sul e Zimbabwe). A sede da empresa gestora deste sistema ferroviário está na cidade de Maputo. A rede rodoviária permite a ligação de Maputo com a Suazilândia, África do Sul e o resto do território moçambicano. Está ainda em Maputo o Aeroporto Internacional de Maputo, o maior do país.

O trabalho de Jorge e Melo (2011), diz ainda que a actual estrutura territorial da cidade é reflexo de diferentes contextos históricos, destacando-se: (i) o colonial, que esteve na génese da sua formação; (ii) o pós independência, de inspiração socialista; e (iii) o neoliberal, após a abertura à economia de mercado no final da década de 1980. Ao longo do tempo, os processos e dinâmicas de intervenção urbana têm contribuído para, ou sido incapazes de contrariar, a dualidade socioespacial existente, acentuada pela urbanização acelerada - que se inicia na 
década de 1950 e se intensifica durante a guerra civil - e agravada no presente contexto de globalização neoliberal, segundo autores como Jenkins e Wilkinson (2002) e Raposo (2007).

O estudo realizado pelo Conselho Municipal da Maputo (2010) realça que, após a independência, a expansão do crescimento urbano não correspondeu às previsões planificadas devido a guerra e a carência de infraestruturas e recursos. O êxodo de refugiados de guerra, vindos da área rural, em busca de protecção na cidade, agravado pela incapacidade do Estado de acompanhar a demanda e prover habitação, motivou as ocupações irregulares, prevalecendo o processo de auto-construção. A tendência foi a densificação de zonas já urbanizadas ou de zonas periurbanas carentes de infraestruturas e serviços básico.

O mesmo documento de 2010 diz ainda que nos assentamentos informais de Maputo vivem hoje cerca de 800.000 pessoas - 69,5\% da população do município. Nos bairros informais as pessoas vivem em péssimas condições, sem água potável e suficiente, sem colecta e tratamento de esgotos, sem ruas e sem drenagem, sem energia eléctrica, sem serviços de remoção de lixos, sem escolas ou postos de saúde, sem comércio organizado, sem campos de jogos, bibliotecas, lugares de culto e com grandes dificuldades de transportes. Nesses bairros a população cresce mais, e mais depressa, que nos bairros urbanizados e isso é um problema que cada dia se agrava.

A pesquisa de 2006 elaborada pela Direccão Nacional de Planeamento e Ordenamento Territorila em Moçambique relata que neste processo de desenvolvimento a estruturação do espaço da cidade colonial, assim como as infraestruturas públicas, em geral, não sofreram alterações importantes. A parte considerada de cimento manteve-se. Os seus bairros periféricos, onde se encontrava a maioria da população local, foram os únicos que se ampliaram todos eles com o mesmo nível precário de serviços.

Por outro lado a parte descritiva do Plano de Estrutura da Cidade de Maputo (2008), informa que a cidade da Matola, capital da província de Maputo, é o principal centro industrial do país, e concentra o comércio grossista ${ }^{7}$. Possui instalações portuárias especializadas - cais de minério - interligadas com o porto de Maputo.

Matola, é hoje, presidida também por um presidente eleito por sufrágio universal e suas vereações. Está dividida em postos administrativos e bairros.

\footnotetext{
${ }^{7}$ Actividade comercial que consiste na aquisição de produtos directo ao importador ou ao produtor e na venda por atacado (por volume importante), realizando-se em instalações adequadas à natureza dos produtos ou bens a comercializar, não efectuando venda ao público consumidor.
} 


\section{Tabela 2 - Cronograma dos planos directores para a Área Metropolitana de Maputo ${ }^{8}$}

\begin{tabular}{|c|c|c|c|}
\hline Data & Planos directores & $\begin{array}{l}\mathrm{N}^{\circ} \text { de habitantes } \\
\text { (hab) }\end{array}$ & Factos \\
\hline 1887 & $\begin{array}{l}\mathrm{I}^{\circ} \text { Plano de Urbanização da } \\
\text { Cidade de Maputo }\end{array}$ & & \\
\hline 1898 & & $\begin{array}{l}\text { Cidade de Maputo } \\
\text { com } 2.400 \text { hab }\end{array}$ & \\
\hline 1945 & & $\begin{array}{l}\text { Criação do Posto da } \\
\text { Matola }\end{array}$ & \\
\hline 1950 & & $\begin{array}{l}\text { Cidade de Maputo } \\
\text { com } 100.000 \text { hab }\end{array}$ & \\
\hline $1952 / 5$ & $\begin{array}{l}\text { II }^{\circ} \text { Plano de Urbanização da } \\
\text { Cidade de Maputo (Não } \\
\text { implementado) }\end{array}$ & & \\
\hline 1960 & $\begin{array}{l}\text { III }^{\circ} \text { Plano de Urbanização da } \\
\text { Cidade de Maputo }\end{array}$ & $\begin{array}{l}\text { Cidade de Maputo } \\
\text { com } 180.000 \text { hab }\end{array}$ & $\begin{array}{l}\text { Início do processo de } \\
\text { urbanização da Matola }\end{array}$ \\
\hline 1970 & & $\begin{array}{l}\text { Cidade de Maputo } \\
\text { com } 380.000 \text { hab }\end{array}$ & \\
\hline 1972 & & & $\begin{array}{l}\text { Elevação da Matola a } \\
\text { categoria de cidade }\end{array}$ \\
\hline 1975 & Independência de Moçambique & & $\begin{array}{l}\text { Constituição da República } \\
\text { Popular de Moçambique }\end{array}$ \\
\hline 1980 & & & $\begin{array}{l}\text { Integração de Matola à } \\
\text { cidade de Maputo }\end{array}$ \\
\hline 1987 & & & $\begin{array}{l}\text { Autonomia da Cidade da } \\
\text { Matola }\end{array}$ \\
\hline 1990 & & & $\begin{array}{l}\text { Constituição da República de } \\
\text { Moçambique }\end{array}$ \\
\hline 1998 & & & $\begin{array}{l}\text { I }^{\mathrm{a}} \mathrm{s} \text { eleições autárquicas de } \\
\text { Moçambique }\end{array}$ \\
\hline 2004 & & & $\begin{array}{l}\text { Constituição da República de } \\
\text { Moçambique }\end{array}$ \\
\hline 2008 & $\begin{array}{l}\text { IV }^{\circ} \text { Plano de Urbanização da } \\
\text { Cidade de Maputo }\end{array}$ & $\begin{array}{l}\text { Cidade de Maputo } \\
\text { com 1.150.000 hab }\end{array}$ & \\
\hline 2010 & $\begin{array}{l}\text { Plano de Urbanização da Cidade } \\
\text { da Matola }\end{array}$ & $\begin{array}{l}\text { Cidade da Matola } \\
\text { com 648.263 hab }\end{array}$ & \\
\hline
\end{tabular}

O Gráfico 1 apresenta de maneira sucinta, alguns dados e eventos importantes ocorridos na Área Metropolitana de Maputo desde os finais do séc. XIX até aos nossos dias.

Segundo Araújo (2006), parece evidente que o espaço urbano dessas duas grandes urbes moçambicanas - Maputo e Matola - apresenta, em si, mais que uma realidade espacial, conformando uma dualidade que se caracteriza, em simultâneo, pelo complementar e o antagónico. Pelo complementar, porque sendo unidades dum mesmo conjunto administrativo, a cidade-município, elas não existem só por si e para si, mas numa interrelação dinâmica em

\footnotetext{
${ }^{8}$ Fonte: o autor.
} 
que cada unidade territorial se completa com as restantes e que extravasa os próprios limites da urbe. Pelo antagónico, porque nas diferentes unidades espaciais se observam características próprias de grupos com diferentes oportunidades de acesso a bens e serviços, competindo e se complementando em condições marcadas pela desigualdade.

\section{Problemas relacionados com a mobilidade urbana}

Segundo Duarte at al (2008), o crescimento acelerado dos centros urbanos nos últimos anos, e o aumento do número de transportes individuais no total de viagens motorizadas, vêm desconfigurando o papel das cidades: o de proporcionar qualidade de vida e qualidade de circulação, intensificando os conflitos entre modos de deslocamento e gerando gastos económicos vultosos, na tentativa de viabilizar o fluxo de veículos motorizados.

Considerando que o planeamento do sistema de transporte público deve ser realizado em conjunto com o planeamento do transporte em geral, incluindo sistema viário e trânsito, é importante ter-se claro que o transporte público é o modo mais indicado para as cidades, devendo, portanto, ter-se preferência em relação aos modos individuais e semipúblicos, vide Ferraz e Torres (2004).

Ainda para Ferraz e Torres (2004), é também importante que o planeamento do transporte urbano seja realizado em conjunto com o planeamento do crescimento e do desenvolvimento da cidade, pois transporte e ocupação/uso do solo são actividades intimamente relacionadas. A ocupação e o tipo de uso do solo influenciam na demanda por transporte; a existência de transporte induz a um aumento da ocupação do solo e influi no tipo de uso do mesmo.

Além disso, o transporte urbano, de forma como é hoje planeado e produzido, funciona como indutor, nem sempre involuntário, da ocupação irracional das cidades. Dentre os problemas mais graves de gestão do transporte público em diversos países em desenvolvimento, sobressaem a carência de estudos e planos, a pouca interacção com o uso do solo e o desenvolvimento urbano; a carência de equipas técnicas especializadas; a fragilidade e/ou inadequação da base legal de suporte à gestão, emprestando ao sector uma significativa instabilidade institucional; e a falta de definição de objectivos estratégicos para o transporte público, vide Ministério das Cidades (2006a). As cidades componentes da Área Metropolitana de Maputo não são excessão à esta regra. 
Porém, é importante recordar que as formas de organização do espaço regional pelas cidades não são do mesmo modo nos diversos países subdesenvolvidos. O facto comum é a presença de uma grande cidade, dominando largamente um imenso território, onde a sua influência se faz sentir sem discussão e sem relação ao qual faz o papel de uma grande cabeça, tal a macrocefalia ${ }^{9}$ de suas funções. A área regional subordinada é tanto mais vasta quanto mais subdesenvolvido for o país; mas variam, também, as formas como a cidade prolonga a sua influência, através desse território. Esta forma de organização já era vista por Milton Santos (1965), e continua válida hoje reflectindo um espaço vivido, um lugar.

O relatório do Plano de Estrutura Urbana da Cidade de Maputo (2008) diz ainda que os municípios de Moçambique, no geral, padecem de alguns problemas comuns no domínio do ordenamento e da ocupação do território municipal. Ainda em Maputo, com a taxa de crescimento urbano que se espera se mantenha mais alta que no resto do país (na ordem dos $10 \%$ contra 5\%), as suas estradas devagar tornar-se-ão congestionadas, como uma rede fechada. O tráfego, primeiro, tomará as vias alternativas, até que estas atinjam também o seu limite de capacidade.

Como revela o relatório da 2009 elaborado pelo Fundo de Desenvolvimento da Comunidade, instituição que actua em Moçambique, em muitas cidades de países em vias de desenvolvimento, o transporte urbano constitui um grande problema. A capacidade limitada, as fracas ligações e os preços altos, implicam que as pessoas pobres por vezes gastem acima de $30 \%$ do seu orçamento no transporte. O problema é que, apesar da limitada capacidade destes serviços nas zonas urbanas, estes ainda não constituiem uma prioridade que deva ser alvo de uma intervenção por parte dos responsáveis municipai

Deste modo, o tratamento da mobilidade deve ser entendido como função pública destinada a garantir a acessibilidade para todos e que, para tal, exige a obediência às normas e prioridades as quais respondam as diferentes necessidades de deslocamento, contribuindo para a redução dos efeitos negativos provocados pelo uso predominante do automóvel segundo a ANTP, (2003).

\footnotetext{
${ }^{9}$ Macrocefalia, neste caso, considera-se a concentração dos serviços urbanos e infraestrutura sócio-económica em determinado centro urbano acirrando deste modo dependência das regiões em redor por estes locais.
} 


\section{Gestão urbana e sua relação com a mobilidade urbana na Área Metropolitana de Maputo}

A expansão urbana da cidade de Maputo realiza-se com o crescimento dos seus bairros periféricos e surgimento de outros, no entanto, a cidade da Matola, alguns bairros do distrito de Marracuene, limítrofes ou não, bem como dos distritos de Boane e Moamba fazem também pressão a este centro urbano.

A Área Metropolitana de Maputo possui, na área de gestão da mobilidade urbana,o Conselho Municipal da cidade de Maputo, o governo da província de Maputo, o Conselho Municipal da cidade da Matola, o Ministério dos Transportes e Comunicações por intermédio da Direcção Nacional dos Transportes de Superfície, a Administração Nacional de Estradas (ANE), o Instituto Nacional de Transportes Terrestres (INATTER), a Federação Moçambicana de Transportadores Rodoviários (FEMATRO), a Associação dos Transportadores Terrestres e Rodoviários de Maputo (ATROMAP) e a União dos Transportadores de Maputo (UTRAMAP), como principais instituições intervenientes.

Da parte do município de Maputo, os pelouros de Transportes e Trânsito, do Planeamento Urbano e Ambiente, e de Infraestruturas são os principais intervenientes na gestão da mobilidade urbana.

Estes pelouros têm sob sua responsabilidade o serviço de manutenção da rede de estradas; a construção de passeios públicos; a gestão e sinalização do tráfego viário; a manutenção de parques públicos, arborização e limpeza; a drenagem pluvial.

Considerada como área-chave de acessibilidade devido a sua localização e sendo parte integrante da metrópole de Maputo, a cidade da Matola tem como responsável pela mobilidade urbana a vereação de Obras e Infraestruturas municipais. De recordar que as vias principais de ligação quer rodoviárias quer ferroviárias entre a capital do país e países vizinhos como a África do Sul - via Estrada Nacional 4, EN4 - e a Suazilândia - via Estrada Nacional 2, EN2 - atravessam o coração deste centro urbano (Figura 3). 


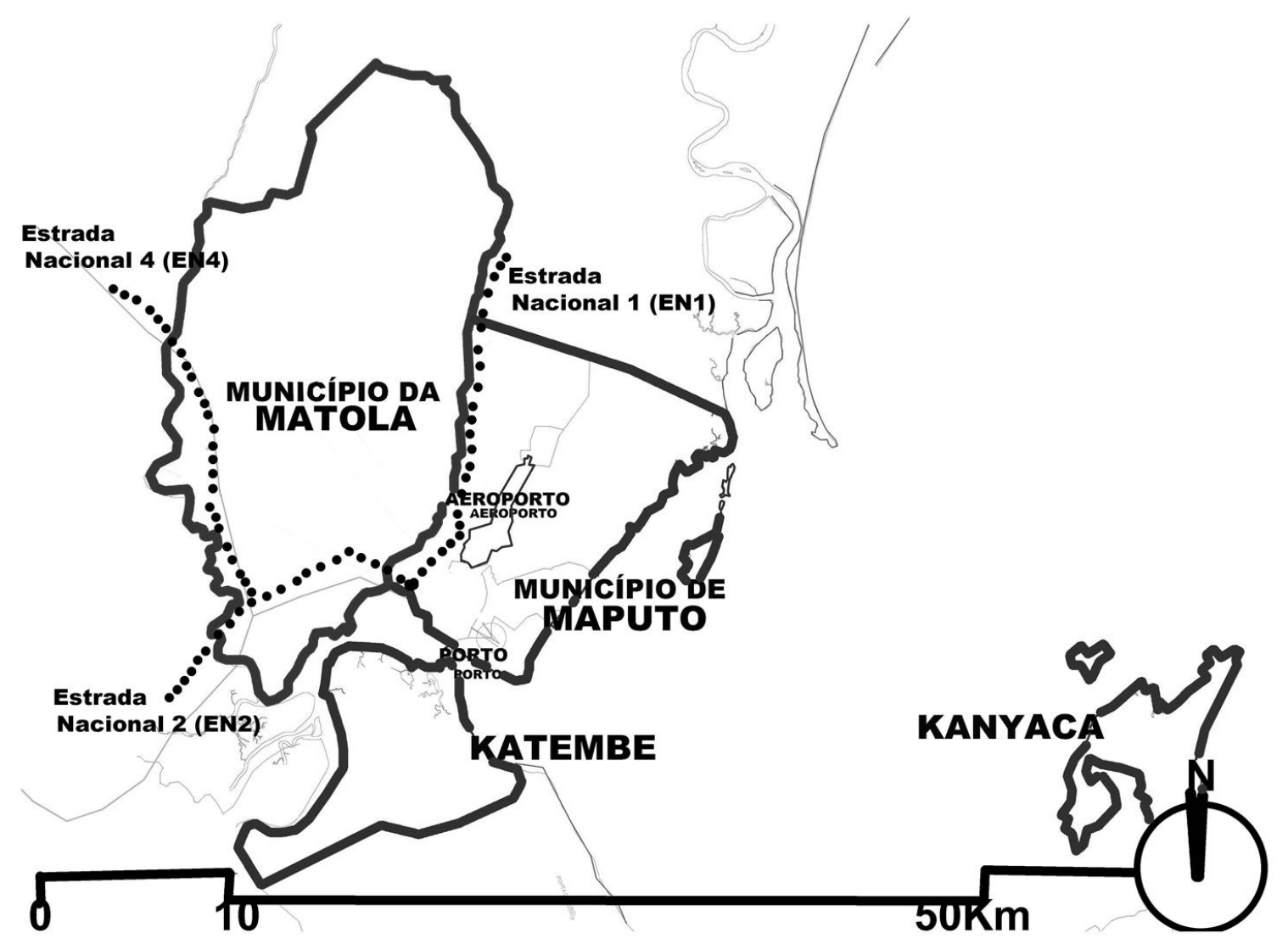

Figura 3 - Estradas Nacionais Localizadas na Metrópole de Maputo ${ }^{10}$

Por sua vez o Ministério dos Transportes e Comunicações, por meio da Direcção Nacional de Transportes de Superfície, coordena e supervisiona o desenvolvimento dos transportes de superfície; da Administração Nacional de Estradas (ANE) planifica o desenvolvimento de rede de estradas públicas, implementa programas nacionais de estradas, aprecia e propõe a regulamentação administrativa e técnica sobre estradas, e recomenda projectos de estradas para financiamento;e do Instituto Nacional de Transportes Terrestres (INATTER) regula, fiscaliza e supervisiona as actividades desenvolvidas no ramo dos transportes terrestres visando satisfazer as necessidades de mobilidade de pessoas e bens.

Outros intervenientes no sector de mobilidade urbana na Área Metropolitana de Maputo são a Federação Moçambicana de Transportadores Rodoviários (FEMATRO), que também faz o controle das actividades de transporte de público de passageiros realizado pelo sector privado; a Associação dos Transportadores Terrestres e Rodoviários de Maputo (ATROMAP) e a

\footnotetext{
${ }^{10}$ Fonte: o autor.
} 
União dos Transportadores de Maputo (UTRAMAP) que realizam estudos, defendem os interesses e prestam assistência técnica aos transportadores associados nas cidades de Maputo e Matola, respectivamente.

Matsinhe diz no seu estudo (2008) que em Moçambique, compete aos municípios a efectivação de investimentos públicos na rede viária urbana e rural, e nos transportes colectivos exclusivamente na área da autarquia.

Maputo tem como dinâmica um centro da cidade capital caracterizado principalmente por actividades comerciais, áreas de emprego e outros serviços estando as zonas residenciais, na sua maioria, localizadas na periferia da cidade de Maputo, na cidade da Matola e arredores. A cidade da Matola é ainda uma potencial zona de desenvolvimento, onde há uma grande concentração industrial incluindo uma das maiores fábricas mundiais de alumínio, a MOZAL, é considerada cidade mais industrializada do país.

Actualmente, a África subsariana conhece um dos índices de urbanização mais elevados do mundo e tornar-se-á, durante os próximos 30 anos, mais urbana do que rural. Moçambique não se afasta desta dinâmica, uma vez que as suas cidades, e sobretudo a sua capital, conhecem um crescimento demográfico e espacial muito rápido a partir dos anos 1980. Enquanto a antiga capital colonial - Lourenço Marques, hoje Maputo - contava apenas com 375.000 habitantes na altura da independência, em 1975, a conurbação formada hoje pelas cidades de Maputo e da Matola agrupa agora cerca de 1.800.000, de acordo com os dados do último recenseamento realizado em 2007. Este crescimento demográfico deve-se principalmente à duplicação da população da cidade da Matola, antigamente considerada a cintura industrial da capital e que entrou, progressivamente, "em colisão" com a sua vizinha cidade de Maputo, durante os últimos vinte anos. Matola é considerada actualmente como sendo a segunda cidade mais importante do país, depois de Maputo e o continuum urbanizado constituído pelas duas cidades agrupa cerca de 50\% da população urbana de Moçambique, vide Mounier (2010).

A guerra civil, que persistiu de 1976 à 1992, incitou uma migração sem precedentes para as zonas urbanas. O fim da guerra civil só aumentou a pressão urbana, pois os moçambicanos estavam desesperadamente a procura de oportunidades de emprego, acesso à saúde e educação nas cidades. A estrutura organizacional urbana complicada herdada dos portugueses não previa esta afluência, e a maioria dos novos migrantes fixou-se em residências informais, vide UN-Habitat (2007) 
Assim, para Baía (2008), a fusão entre a cidade e o campo ocorreu no meio urbano, pois apesar dos investimentos quase nulos no desenvolvimento das cidades, estas continuaram a receber incrementos de população rural quer como resultado das diferenças de desenvolvimento, quer pela insegurança no campo provocada pela propagação do conflito armado.

Baía (2008) refere ainda que o actual fenómeno da reclassificação urbana, cujos objectivos carecem de investigação, não só atribui novas especificidades ao processo urbano em Moçambique, como introduz, administrativamente, áreas com características sociais, económicas e culturais rurais dentro dos limites dos centros urbanos. É neste contexto que as cidades em Moçambique combinam a forma dispersa de ocupação do solo, característica do meio rural, e a forma concentrada específica do meio urbano, constituindo, por essa via, uma entidade contraditória.

Desse modo, e como refere Araújo (2003 apud Baía, 2008, p.8), as áreas peri-urbanas funcionam como espaços onde a população imigrante constrói residência transitória no seu percurso pela procura de inserção na economia urbana; também, são espaços procurados pela população com alto poder aquisitivo e vivendo no centro da cidade para fixação de uma segunda ou terceira residência, num processo não isento de conflitos de posse de terra. Essas áreas funcionam ainda como reservas para expansão urbana planificada, mas também são utilizadas pelo estado para o reassentamento de população retirada de áreas consideradas impróprias para habitação ou sujeitas às intervenções planificadas.

Estando a metrópole de Maputo sob pressão exercida pelo actual parque automóvel, levantase a necessidade de adopção de medidas tanto para o arranjo institucional na área de gestão da mobilidade quanto no redimensionamento e reabilitação da infraestrutura e mobiliário urbano que servem aos modos de transporte rodoviário, ferroviáro, fluvial e marítimo.

No entanto, a metrópole de Maputo não é ainda pensada e planeada como um todo. A perspectiva fracturada desta constitui um grande problema que necessita de uma urgente intervenção pois a dinâmica económica é impulsionada pelos cidadãos que residem fora dos centros urbanos consolidados das cidades de Maputo e Matola. No entanto, são estes cidadãos que enfrentam as consequentes dificuldades resultantes da falta de coordenação e colaboração entre as instituições responsáveis pela gestão dos territórios administrativos que compõe a metrópole. 
Os mecanismos de cooperação intermunicipal permitem, no respeito da personalidade própria de casa município, a gestão em comum dos assuntos de interesse colectivo, tanto na zona rural como na aglomeração urbana. Os modos de cooperação intermunicipal podem ser extrememente variados. Se alguns podem ser informais ${ }^{11}$, outros podem ser institucionalizados e podem dar nascimento à estruturas de direito privado ${ }^{12}$ ou empresas interautárquicas ${ }^{13}$ vide Matsinhe, (2008). No entanto, não há até ao momento em Moçambique, o registo de existência de uma única empresa intermunicipal.

Segundo Lordello (1996), com base na análise das experiências internacionais poder-se-ia, ainda, identificar três grandes modalidades institucionais para melhor enfrentar o problema de gestão metropolitana. A primeira, alicerçada na criação de entidades metropolitanas de corte mais compreensivo, tomando por base um acordo voluntário entre agências governamentais autônomas. A segunda prioriza a criação de um número reduzido de agências metropolitanas especializadas - tomando por base um acordo voluntário ou legislação compulsória - com o objectivo de equacionar questões específicas (transportes, colecta e destinação de lixo, abastecimento de água, meio ambiente, etc). Por fim, ter-se-iam formas compulsórias de gestão metropolitana compreensivas. Nesse caso, uma das alternativas, menos difundida, preconiza a criação de uma superprefeitura (superautarquia), mediante a fusão ou amálgama dos governos municipais.

Falando-se concretamente de Maputo, as da cidade Matola e Maputo, distritos de Marracuene, Boane, Moamba e até Namaacha e Matutuíne são unidades territoriais que pelo sistema urbano-metropolitano e desafios sociais e económicos já clamam por um arranjo institucional de nível regional-metropolitano.

\footnotetext{
${ }^{11}$ A cooperação informal entre municípios pode revestir diversas formas, respectivamente acordos, convecções e conferências, mas também a forma de cartas intermunicipais de desenvolvimento e de urbanização e de acordos contratuais, vide Matsinhe (2008).

${ }^{12}$ Os municípios podem recorrer a este tipo de este tipo de estruturas nos casos em que desejem institucionalizar a sua cooperação criando um organismo distinto encarregue da gestão dos seus interesses comuns. Trata-se de estruturas cujo funcionamento conserva uma certa flexibilidade, designadamente no que tange os meios materiais, humanos e financeiros, vide Matsinhe (2008).

${ }^{13}$ A possibilidade da associação tendo em vista as obras de interesse intermunicipal está prevista, ainda que implicitamente, no n.3 do art.45 da Lei n. ${ }^{\circ}$ 2/97, de 18 de Fevereiro de $1997,2^{\circ}$ Suplemento, I Série - BR N.7 de 18 de Fevereiro. As empresas intermunicipais devem ter um objecto específico, podendo gerir diversas obras ou serviços quando complementares, vide Matsinhe (2008).
} 


\section{Transporte público urbano na Área Metropolitana de Maputo}

Matos (2008) diz que com abertura de Moçambique para economia do mercado nos finais da década de 1980, começaram a emergir pequenos empreendedores em várias áreas de actividade, prestando serviços que outrora eram exercidos pelo Estado por meio de empresas estatais. O sector de transporte não escapou à regra, e começaram a aparecer pequenos transportadores que, de forma tímida e ilegalmente, transportavam passageiros em carrinhas sem condições mínimas de segurança, visando responder à cada vez mais crescente procura de transporte em quase todo o País, com grande ênfase nos centros urbanos, tendo na cabeça da lista as cidades de Maputo e Beira. De salientar que, dada a maneira como tudo aconteceu, não havia legislação que regulasse o exercício da actividade de transporte por pequenos operadores, daí que foi necessário aprovação dos instrumentos normativos, os decretos 24/89 e 92/89, Regulamento de Transporte em Automóveis (RTA) e criação do transporte semicolectivo de passageiros.

Em 1996, foi também aprovada a Política de Transportes e Comunicações, através do decreto ministerial $\mathrm{n}^{\circ} 5 / 96$, com o objectivo de traçar as linhas gerais de orientação para o sector. Neste mesmo ano foi actualizado o RTA, através do decreto ministerial $n^{\circ} 15 / 96$, vide Matos (2008).

Matos (2008) diz ainda que apesar de aprovação destes instrumentos, a situação não melhorou os problemas começaram a surgir, dentre os quais, se destacam: acidentes de viação; condução sem observância das regras básicas de segurança rodoviária e de conforto; mudanças constantes de rotas, criando desequilíbrios na oferta; conflitos entre operadores; insatisfação do público utente dos serviços.

Segundo dados que podem ser considerados actuais o cenário de oferta de transportes públicos comparando algumas cidades africanas é o seguinte. 


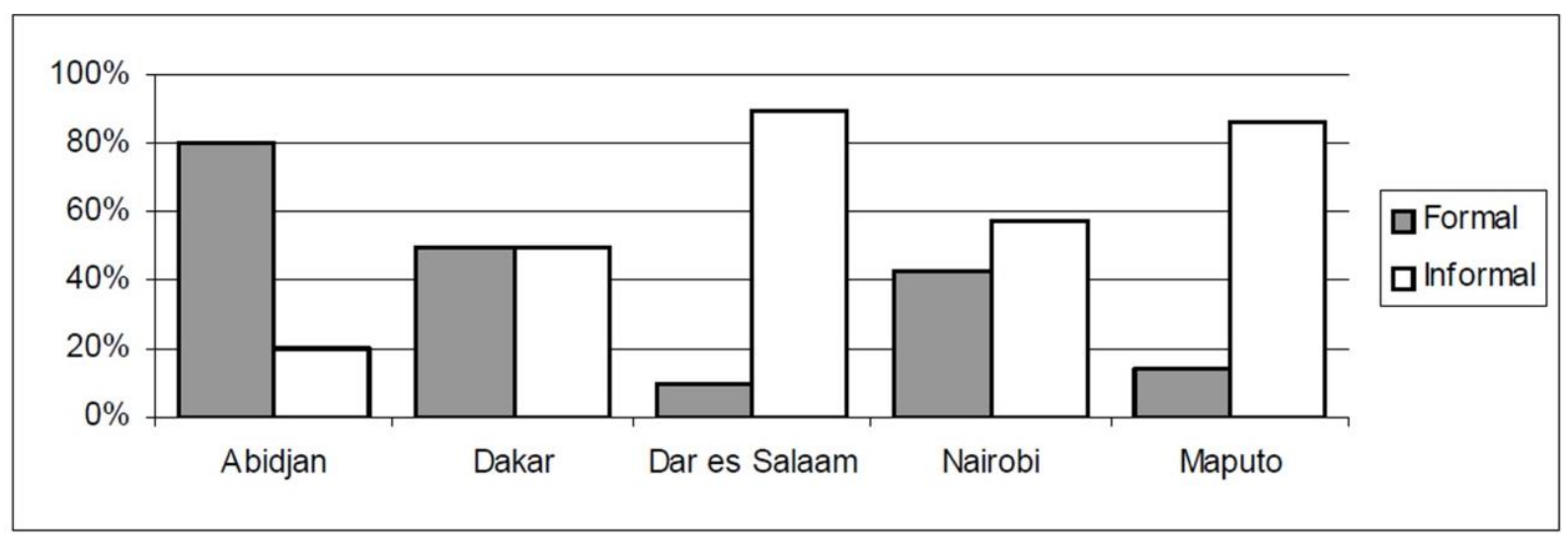

Figura 4 - Oferta de transportes públicos em algumas cidades africanas ${ }^{14}$

Este cenário pode ter piorado em Maputo. A oferta por parte dos transportadores privados baixou consideravelmente, não tendo o déficit sido suprido pelo sector de transporte público formal. As condições de transporte de passageiros oferecida nos dias de hoje pelos serviços de transporte público de passageiros, falam por si.

Segundo Verás (2001) a cidade contemporânea se explicita na metrópole. Se seus espaços são heterogéneos - zonas rurais, de habitação da pobreza, da indústria tradicional, da indústria moderna, de serviços sofisticados, de serviços de baixa qualificação, condomínios fechados de alta renda, shopping centers, zona de negócios, hotéis e parques de convecções, confronto entre os iguais e os diferentes -, o tempo materializado nesses lugares é extremamente dinâmico, pois a co-presença ensina aos homens, territorializa e (des)territorializa e (re)territorrializa, trata-se assim, de tempo humanizado, não-natural.

A população das cidades de Maputo e Matola é dominantemente localizada em bairros que se situam em distâncias entre 9 quilómetros a 30 quilómetros, vide FEMATRO, (2011).

Associado a estes factos, o actual cenário do transporte público urbano em Moçambique, especificamente na Área Metropolitana de Maputo, não é tão saudável. Pois, como se pode depreender:

- O movimento dos veículos de transporte colectivo de passageiros é pendular, servindo, alternadamente a periferia da cidade de Maputo e a cidade da Matola, e o centro da cidade de Maputo aumentando o número de viaturas nas horas de ponta;

\footnotetext{
${ }^{14}$ Fonte: Plano de Estrutura Urbana da Cidade de Maputo (2008).
} 
- Os transportadores colectivos-privados de passageiros param onde quer que os passageiros peçam para embarcar ou desembarcar, normalmente transportam um número superior à capacidade designada de passageiros sentados;

- Os transportadores privados tendem a interromper o tráfego quando param no meio do caminho e são acusados de causarem muitos acidentes. Cada minibus está licenciado para operar apenas numa única rota, que está indicada no vidro da frente e de trás com os nomes das terminais de origem e de destino - ou principais pontos de recolha de passageiros;

- Os minibuses partem assim que lotam, facto que é frequente, dada a sua pequena capacidade, e grande demanda por parte dos cidadãos;

- Durante os períodos de pico, os minibuses partem numa média horária de cerca de 10 minutos. Eles operam sob a tutela de duas associações: Associação dos Transportadores de Maputo (ATROMAP), que opera na cidade de Maputo; e União dos Transportadores de Maputo (UTRAMAP), que opera na cidade da Matola e entre Maputo e a Matola;

- O serviço privado de transporte de colectivo de passageiros, vulgo chapas ${ }^{15}$, funciona com apenas um motorista e cobrador que fica na porta de saída e comanda a marcha do veículo, mandando-o parar, arrancar, anunciar a rota que vão executar e inclusive "chamar" passageiros que se encontram na via pública;

- As rotas dos transportes colectivos de passageiros, exploradas por operadores privados, são por vezes encurtadas ou alteradas sem aviso prévio e contra a vontade dos utentes contrariando o preconizado na lei;

- Para as empresas municipais de transporte público, recentemente criadas na Área Metropolitana de Maputo, a tarifa cobrada desde outubro de 2012 é de 7,00 Meticais (MT) [cerca de US\$ 0,25]. Para os transportadores públicos de passageiros do sector privado as tarifas são variáveis em função da distância a percorrer, sendo de 7,00 Meticais (MT) [cerca de US\$ 0,25] para distâncias até 10 quilómetros e de 10,00 Meticais (MT) [cerca de US\$ 0,36] para distâncias superiores a 9 quilómetros;

- O conceito de origem/destino é o que ainda continua em funcionamento, existindo apenas alguns apeadeiros formais na zona de cimento da cidade de Maputo;

- A velocidade comercial é elevada, em especial nas artérias principais, chegando a atingir valores acima dos $40 \mathrm{~km} / \mathrm{h}$;

\footnotetext{
${ }^{15}$ Nome atribuído às viaturas dos operadores privados que realizam a actividade de transporte colectivo de passageiros.
} 
- A concorrência entre operadores privados é também acirrada, levando em certa medida a um caos no trânsito urbano com paragens ao longo das avenidas ou ruas principais para recolher "mais um passageiro", gerando filas de trânsito, acidentes e/ou manobras perigosas. Esta situação faz com que o tráfego rodoviário esteja normalmente congestionado agravando-se a situação nas horas de ponta;

- As condições de segurança das viaturas não são satisfatórias no seu geral, apresentando algumas deficiências mecânicas (travões, carroçaria), várias deficiências em termos de sinalização e conforto, gases de escape com fumaça - sinal de motor, bomba injectora ou filtros em péssimas condições - e perdas de óleo;

- Existem operadores que não estão registados nas devidas associações e Direcção Municipal de Transportes e Trânsito da cidade mas que exercem a actividade de transporte de passageiros sem que as viaturas e/ou os motoristas estejam habilitados para tal;

- Os utentes do transporte público na Área Metropolitana de Maputo estão sujeitos a um tempo médio de espera nos apeadeiros de pelo menos uma hora;

- Devido a crise de transportes que se fez sentir na Área Metropolitana de Maputo desde os meádos de ano 2011, as autoridades responsáveis pela gestão do transporte público de passageiros chegaram a permitir que cidadãos que tenham viaturas com capacidade para transportar acima de 15 passageiros, o façam durante nas horas de ponta mesmo que não estejam registados para exercer tal actividade.

Com base no cenário acima descrito pode-se afirmar que o padrão de intervenção na gestão urbana da metrópole de Maputo contribui para fenómenos de exclusão socioespacial e para a permanência da dualidade na prestação de serviços para os cidadãos metropolitanos. Esta segregação socioespacial pode ser entendida como a exclusão da população de baixos recursos dos benefícios proporcionados pelo território urbano, destacando-se: as infraestruturas básicas (saneamento, abastecimento de água, rede eléctrica, viária e de drenagem), a habitação condigna e os espaços públicos qualificados, essenciais à criação de boas condições de habitabilidade e de vida.

Ainda segundo o estudo encomendado pela Federação Moçambicana dos Transportadores Rodoviários (2008 apud Matos, 2008, p.6), os transportadores licenciados ao nível nacional eram, em 2006, cerca de 12.481 viaturas para o exercício do transporte rodoviário, 8.309 para o transporte colectivo e semi-colectivo, 994 para o transporte interprovincial e 3.180 para o transporte de carga. 
Este estudo revela ainda que o ambiente do transporte rodoviário em Moçambique é caracterizado por: uma infraestrutura rodoviária deficiente, ocupação de passeios e bermas para outros fins, indisciplina e insegurança no transporte semi-colectivo de passageiros, fraca capacidade de fiscalização dos transportes rodoviários, pouca oferta de transporte rodoviário, fraca capacidade de gestão por parte dos operadores, mau estado técnico dos veículos, inexistência de inspecções periódicas obrigatórias, falta de implementação do seguro obrigatório, fraca assistência técnica agravada pela proliferação de peças sobressalentes de baixa qualidade, concorrência desleal perpertrada pelos transportadores não profissionalizados, violação do código de estrada e seu regulamento, sistema de formação e avaliação de condutores ineficaz, fraca organização dos transportes de passageiros, insuficiente preparação técnica dos intervenientes no sistema de transporte rodoviário e fraca formação do pessoal de oficinas automóveis carga, vide USAID (2008).

Segundo Saboya (2000), existem diversas tentativas de definição do processo ideal de planeamento urbano, com maior ou menor grau de detalhamento, todas convergem, entretanto, para uma mesma estrutura básica de passos a serem percorridos no modelo racional de planeamento: Descrição do sistema, definição do problema, determinação dos objectivos, definição das alternativas, implementação, e monitoramento.

Entretanto, a ausência de interacção e articulação entre os órgãos de poder vinculados ao governo e de gestores da questão urbana - municípios, governo da província e cidade, Caminhos de Ferro de Moçambique, Transportes Públicos de Maputo - tem inibido oudificultado iniciativas fundamentais de minimização do problema de mobilidade na Área Metropolitana de Maputo e não só. 


\section{Conclusão}

Com a discussão sobre a relação mobilidade urbana vs gestão territorial, desenvolvida nos 6 pontos acima descritos, espera-se que o presente trabalho venha contribuir e servir de base para outras pesquisas mais aprofundadas em volta do tema mobilidade urbana em Moçambique.

Em Moçambique, a expansão do território da Área Metropolitana de Maputo é evidente sendo caracterizada pelo seu sistema fluxos e de difícil delimitação correndo-se o risco de redução da sua natural dinâmica de desenvolvimento.

Esta área metropolitana é definida no presente trabalho como a unidade aglutinadora de natureza urbano-regional com polarização compartilhada entre as centralidades de Maputo e Matola. Alguns indicadores como o tamanho populacional, o PIB, a intensidade de deslocamentos de pessoas que estudam ou trabalham em munícipios que não sejam de residência podem confirmar essa tendência aglutinadora da Área Metropolitana de Maputo.

O sector de planeamento de transportes, por exemplo, para construir o seu modelo de alocação de tráfego, necessita de informações referentes à localização de residência e trabalho, contidas de forma desagregada nos cadastros tributários dos órgãos municipais. Mediante operações de agregação, essas informações podem ser reformatadas para servirem como input, de forma precisa, confiável e facilmente actualizável. Problemas comuns, que transcendam as fronteiras municipais poderiam ser solucionados com a introdução do planeamento metropolitano do transporte em Moçambique.

Propõe-se desta maneira, como ponto de partida para a revitalização da situação dos transportes públicos urbanos da Área Metropolitana de Maputo, a reestruturação do arranjo institucional no sector de gestão urbana da Área metropolitana de Maputo. O conjunto de circunscrições territoriais que a compõe deve ser pensado como um todo com base na articulação e coordenação entre as várias entidades de gestão que influem na sua mobilidade e gestão urbana.

Portanto este é um tema que necessita de um urgente debate e consequente implementação à nível nacional. As políticas públicas deveriam considerar estas componentes perspectivando uma melhoria na resolução da questão urbana. Há, deste modo, necessidade de definição de 
critérios legais e constitucionais nas suas atribuições para que se facilite a capacidade de enfrentar os problemas relacionados com as regiões metropolitanas

Uma alternativa que poderia melhorar a cooperação institucional seria a constituição de um arranjo institucional intergovernamental voluntário, no qual as autoridades governamentais existentes definam em conjunto e por consenso as directrizes que conduzam a gestão regional das ciscunscrições territoriais das quais sejam responsáveis.

Conclusivamente pode-se dizer que os processos de mudança no meio urbano estão directamente relacionados com os sistemas político, económico e social. Os actores na gestão e mobilidade urbana em Maputo, variam e assumem diferentes papéis ao longo do tempo. A percepção, no seu todo, dos eventos que ocorrem na metrópole requere um arranjo nas instituições intervenientes na gestão urbana e no entendimento da necessidade de melhor coordenação entre elas.

A presente pesquisa teve como limitações o facto de: terem sido programadas algumas entrevistas semi-estruturadas com algumas personalidades influentes na gestão dos municípios componentes da metrópole de Maputo e não ter sido possível realizá-las por problemas de agenda dos mesmos; a influência da subjectividade do pesquisador na análise e discussão dos dados foi outra limitação tendo sido usados, para minimizá-la, a consulta e uso de diversas fontes de dados e teorias.

Outra limitante esta relacionada com os documentos disponibilizados para a recolha e análise dos dados. Foi usado material em forma de leis e decretos, relatórios internos das instituições, e ainda outros dados recolhidos nas homepages das instituições. Realçar ainda que a ausência de uma base de dados minimamente estruturada para consulta, a relativa ausência de outras pesquisas e estudos sobre a situação de gestão urbana, no geral, em Moçambique é também uma limitante a considerar. 


\section{Referências}

Araújo, M. G. M. (2006) Espaço urbano demograficamente multifacetado: As cidades de Maputo e da Matola. Disponível em: www.apdemografia.pt. Acesso em: 08 abr. 2012.

Araújo, M. G. M. (1999) Cidade de Maputo. Espaços contrastantes: Do urbano ao rural. Disponível em: www.ceg.ul.pt. Acesso em: 06 mar. 2012.

Azevedo, S. e Guia, V. R. M. (2000) Governança metropolitana e reforma do Estado. O caso de Belo Horizonte. Revista Brasileira de Estudos Urbanos e Regionais, n.3. Disponível em: www.anpur.org.br. Acesso em 17 jul. 2012.

Baía, A. H. M. (2008) Reflexões sobre o espaço urbano: A cidade de Nampula. Disponível em: www.codesria.org. Acesso em: 16 mar. 2012.

Brasil - Associação Nacional de Transportes Públicos - ANTP (2003) Mobilidade e cidadania. São Paulo.

Brasil - Ministério das Cidades (2006a) Curso de gestão integrada da mobilidade urbana. Brasília: Mcidades.

Brasil - Ministério das Cidades (2006b) Política nacional de mobilidade urbana sustentável. Cadernos MCidades n. 6 - Mobilidade Urbana. 2 ed. Brasília: Ministério das Cidades.

Conselho Municipal de Maputo - CMCM (2010) Experiências de Municipios no exercício de Planeamento Urbano e Estratégico em Moçambique. VII Reunião Nacional dos Municípios Moçambicanos, Nampula.

Conselho Municipal de Maputo - CMCM (2008) Plano de Estrutura Urbana do Município de Maputo. Maputo.

Duarte, F., Libardi, R. e Sanchez, K. (2008) Introdução à mobilidade urbana. Curitiba: Juruá.

Federação Moçambicana dos Transportadores Rodoviários - FEMATRO. Estudo de viabilidade económica e financeira: autocarros de 75 lugares. Maputo, 2011.

Ferraz, A. C. C. P. e Torres, I. G. E. (2004) Transporte público urbano. São Carlos: RiMa.

Jorge, S. e Melo, V. (2011) Processos e dinâmicas de (re)produção do espaço (peri)urbano: o caso de Maputo. Second International Conference of Young Urban Researchers, Lisboa.

Matos, A. (2008) População e desenvolvimento na área dos transportes públicos urbanos. Disponível em: pt.scribd.com. Acesso em: 08 Abr. 2012.

Matsinhe, L. (2008) Diagnóstico crítico de 10 anos de descentralização em Moçambique. In: 10 anos de descentralização em Moçambique. Os caminhos sinuosos de um processo emergente. Maputo: NEAD.

Moçambique - Direcção Nacional de Planeamento e Ordenamento Territorial - DINAPOT. (2006) Moçambique melhoramento dos assentamentos informais. Disponível em: www.unhabitat.org. Acesso em: 14 mar. 2011.

Moçambique - Fundação para o Desenvolvimento da Comunidade - FDC. (2009) Opções de intervenção no contexto da pobreza urbana em moçambique: Estudo de caso dos municípios de Maputo e Chimoio. Disponível em: www.fdc.org.mz. Acesso em: 16 mar. 2012.

Moura, R. (2008) Arranjos urbano-regionais: uma categoria complexa na metropolização brasileira. Revista Brasileira de Estudos Urbanos e Regionais, vol. 10, n. 2, pp. 29-49.

Mounier, E. As pessoas com deficiência em Maputo e Matola. 2010. Disponível em: www.handicapinternational.fr. Acesso em: 26 fev. 2012.

Rochefort, M. (1998) Redes e sistemas: Ensinando sobre o urbano e a região. São Paulo: Hucitec. 
Saboya, R. T. (2000) Análises espaciais em planejamento urbano: novas tendências. Revista Brasileira de Estudos Urbanos e Regionais, n. 2, pp. 61-79.

Santos, M. (1965) A cidade nos países subdesenvolvidos. Rio de Janeiro: Civilização Brasileira S. A. $175 \mathrm{p}$.

UN-Habitat, Escritório Regional para África e Estados Árabes. Perfil do sector urbano em Moçambique. 2007. Disponível em: mediamoc.com. Acesso em: 11 out. 2011.

United States Agency for International Development (USAID). Proposta de política dos transportes urbanos para Moçambique. 2008. Disponível em: www.speed-program.com. Acesso em: 20 jun. 2011.

Verás, M. P. B. (2001) Tempo e espaço na metrópole: breves reflexões sobre assincronias urbanas. São Paulo em Perspectiva, vol. 15, n. 1, pp. 3-12. 